\title{
Individual preferences for diet and exercise programmes: changes over a lifestyle intervention and their link with outcomes
}

\author{
Kate Owen ${ }^{1}$, Tahna Pettman ${ }^{2}$, Marion Haas ${ }^{1}$, Rosalie Viney ${ }^{1, *}$ and Gary Misan ${ }^{3}$ \\ ${ }^{1}$ Centre for Health Economics Research and Evaluation, University of Technology Sydney, PO Box 123, \\ Broadway, Sydney, New South Wales 2007, Australia: ${ }^{2}$ Nutritional Physiology Research Centre, University of \\ South Australia, Adelaide, South Australia, Australia: ${ }^{3}$ Spencer Gulf Rural Health School, University of South \\ Australia, Whyalla, South Australia, Australia
}

Submitted 12 December 2008: Accepted 29 May 2009: First published online 6 August 2009

\begin{abstract}
Objective: To investigate the influence of a trial lifestyle intervention on participants' preferences for a range of exercise and diet programmes and whether these differ between successful and unsuccessful participants.

Design: Hypothetical scenarios that describe attributes of diet and exercise programmes were developed using an experimental design. Participants completed an online questionnaire at baseline, 16 weeks and 12 months where they chose their most preferred of three programmes in each of sixteen scenarios. Discrete choice modelling was used to identify which attributes participants emphasised at each time point.

Subjects: Fifty-five individuals who exhibited symptoms of metabolic syndrome and who participated in a 16-week trial lifestyle intervention.

Results: There was a clear shift in programme preferences from structure to flexibility over the intervention. At baseline, emphasis was on individually designed and supervised exercise, structured diets and high levels of support, with Gainers focusing almost exclusively on support and supervision. Losers tended to consider a wider range of programme attributes. After 16 weeks preferences shifted towards self-directed rather than organised/supervised exercise and support was less important (this depended on the type of participant and whether they were in the follow-up group). Cost became significant for Gainers following the end of the primary intervention.

Conclusions: The stated preference method could be a useful tool in identifying potential for success and specific needs. Gainers' relinquishment of responsibility for lifestyle change to programme staff may be a factor in their failure and in their greater cost sensitivity, since they focus on external rather than internal resources.
\end{abstract}

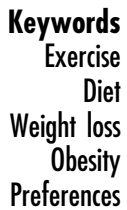

While Jeffery et al.'s study provides insights into participants' feelings and self-reported compliance, little is known about the dynamics between individuals' perceptions of an ideal lifestyle change programme and the reality of an intervention. Evaluation of these dynamics could provide practical insights into why some participants succeed while others fail, and identify issues that hinder or encourage maintenance of a lifestyle change.

Herein we report on a study that examined how individuals' preferences for diet and exercise programmes developed as they participated in a community-based trial lifestyle intervention. The objective was to map their preferences for programme attributes over the course of the intervention and to determine whether there were systematic differences in the preferences of successful and unsuccessful participants. 


\section{Method}

\section{The lifestyle intervention}

The lifestyle intervention was conducted within a regional centre in South Australia with the objective of testing a non-prescriptive lifestyle education programme to manage obesity and cardiometabolic risk factors. Participants were self-selected volunteers who responded to advertisements in the local press. Six hundred and eleven individuals responded to the advertising, of whom 470 could be contacted successfully and 318 were eligible for screening. Three hundred attended for screening, of whom 153 met the criteria of symptoms of metabolic syndrome and were recruited to the intervention study. The participants were randomly allocated to either the control group or to one of two intervention groups, Group A and Group B. Both intervention groups participated in a 16-week programme in which they attended hour-long sessions that included instruction on nutrition, shopping and cooking sessions, and resolving personal issues involved in managing unsuitable diet and low engagement in physical activity. The sessions were run weekly and were modelled in part on the Stanford model of Chronic Disease Self-Management ${ }^{(7)}$, which employs action planning, motivational resources, cognitive symptom management and peer support to aid health behaviour change. Participants were also encouraged to attend an hour exercise class once weekly which incorporated a variety of exercises that could be undertaken at home as well as at a fully equipped gym to which they had been given access. These classes were made available at a range of times over the week as well as immediately following the group sessions. The emphasis in messages on physical activity was to increase the level of physical activity by whatever means are appropriate to a higher level than at present ${ }^{(8)}$. A number of healthy foods (highquality grain bread, cereal, canned tuna and unsalted peanuts) were made available each week free of charge to participants who wished to consume them. Following the 16 weeks, Group A then attended monthly group support sessions over a further eight months whereas Group B had no follow-up. A full description of the intervention is available elsewhere ${ }^{(9)}$.

\section{The stated preference survey}

All 153 participants in the community-based lifestyle intervention were invited to join the preference study which was administered through an online questionnaire* at baseline, 16 weeks and 12 months. We used the Stated Preference method where individuals are presented with sets of options in which the attributes have been systematically varied. Individuals choose their most pre-

\footnotetext{
* Some participants preferred to complete a paper version of the questionnaire. There were no discernible differences in their patterns of response.
}

ferred option in each set. In the current study the options were lifestyle programmes that comprise six attributes (cost, support, exercise duration and exercise structure, diet and outcome) which together produce $4^{4} \times 2^{2}=1024$ possible programmes. A subset of sixteen programmes was identified using a fractional factorial experimental design and modular manipulation was used to create two additional programmes for each set so that we had sixteen choice sets, each containing three programmes. The characteristics of the attributes were developed by drawing on the intervention, previous research and various published guidelines, and are described below. An example scenario is shown in the Appendix.

\section{The attributes}

The diet attribute took one of four forms: 'a daily meal plan based on calorie intake'; 'a daily meal plan based on Australian government recommended serves'; 'weekly meal plans with a range of options'; and 'no targets and no fixed menus but small adjustments in quantities and types of food eaten each day' (e.g. low-fat milk rather than full cream or grain bread rather than white). The last of these (the most flexible) was the approach taken in the intervention.

The two exercise attributes were designed to capture differences in an individual's preferences for frequency and duration of exercise and for his/her preferences for social/independent activities. Frequency and duration were based on recommendations for minimum required exercise to improve fitness $(3 \mathrm{~h} /$ week or $30 \mathrm{~min} / \mathrm{d}$ ) and the desired level of exercise over the longer term to avoid moving from overweight to obesity $(5 \mathrm{~h} /$ week or $45 \mathrm{~min} / \mathrm{d})^{(10)}$. Exercise context could take the form of: 'selfdirected and unsupervised exercise'; 'individual exercise under a set programme designed by an instructor'; 'informal arrangement with friends or exercise group'; and 'commitment to a structured group-based programme'.

The lifestyle intervention provided access to a gym and healthier food options. To assess the effect of similar potential costs, a cost attribute was included. Cost could be either 'no additional cost' or 'modest' (\$AU 15/week).

The support attribute was presented as either fortnightly/ monthly checks or 4- to 6-monthly checks by health specialists or a health club/community centre and including checks on progress with advice and social support.

The final attribute of the programmes was expected outcome and included: an amount of weight loss per week $(0.25 \mathrm{~kg}$ or $0.5 \mathrm{~kg})$ and either no change in body shape but increased well-being and fitness or body shape change.

The wording and characteristics of the attributes in the original sixteen hypothetical programmes were piloted on the first cohort of participants in the lifestyle intervention. Participants were asked to indicate the likelihood of maintaining each programme for 12 months. This format resulted in a large number of participants placing uniformly high (80-100\%) probabilities on their staying 
with a programme and so the format was changed in the main study to that outlined earlier (three programmes in each set). Minor adjustments were also made to the support and exercise duration attributes. The higher level of support was reduced from weekly to fortnightly/ monthly because most respondents thought weekly excessive over a 12-month period and, for similar reasons, daily exercise (i.e. 30 or $45 \mathrm{~min}$ ) was modified to allow one or two days with no exercise in a week.

\section{Analysis}

Model

Participants' first preferences were modelled separately for each period using the conditional logit model ${ }^{*}$ in the Stata statistical software package version 10 (StataCorp., College Station, TX, USA), where

$$
\operatorname{Pr}\left(y_{i}=m \mid z_{i}\right)=\frac{\exp \left(z_{i m} \gamma\right)}{\sum_{j=1}^{J} \exp \left(z_{i j} \gamma\right)} \text { for } m=1 \ldots J
$$

is the probability of choosing programme $m$ from the $J=3$ generic programmes for participant $i$ given the programme's attributes $z$, and where $\gamma$ is a parameter indicating the effect of each feature on choosing the preferred programme.

All variables were dummy-coded except cost. Exercise structure compared different levels of duration and commitment $v$. the most difficult format i.e. $45 \mathrm{~min} / \mathrm{d}$; exercise context used exercising alone with no supervision as the reference level. For outcomes the reference was the most attractive outcome, i.e. $0.5 \mathrm{~kg}$ weight loss and body shape change; and for diet preference, the most regulated diet, i.e. daily calorie counts. Support was dummy-coded with low support as the base and cost was adjusted so that the values were 0 or a daily dollar value (\$AU 15/7).

\section{Results}

Stated preference data currently cannot be modelled using longitudinal methods that also take into account missing observations. This meant that only participants who had provided full data could be included in the analyses. The intervention recruited ninety-three participants in cohorts 2 and 3 (153 overall) and sixty-nine completed the 12 months. Of these, fifty-seven participants $(>75 \%)$ provided sufficient preference data for analysis: Group A (follow-up), $n$ 21; Group B (no follow-up), $n$ 18; Control group, $n$ 18. A check of their preference patterns at baseline against the twelve who were excluded from the analysis indicated no material

\footnotetext{
* Responses were also modelled using Stata's rank-ordered logit but as there was no material difference in the results, the more intuitively appealing conditional logit was adopted for reporting results.
}

differences. Details of screening and attrition during the intervention can be found elsewhere ${ }^{(9)}$. The final sample of fifty-seven comprised $74.5 \%$ women and the average age was 46 (SD 9.8) years.

\section{Group results}

Model results for first preferences for each group at baseline and 16 weeks are shown in Table 1. All models are significant at $p<0.000$ but McFadden's $\rho$ indicates there was substantial heterogeneity in preferences even at 16 weeks when we might expect preferences to converge in the intervention groups.

It is not possible to compare directly the estimates from different samples in discrete choice models because differences in error variation may occur that translate to differences in the scale of parameter estimates. Figure 1 plots the coefficients for the control group $v$. the combined intervention groups; this provides an indication of whether the coefficients across the samples are proportional, which would suggest that differences in parameters are a scaling effect. The direction of attribute weights across groups at baseline was similar but emphases differed. The control group focused almost exclusively on the diet attributes whereas the intervention groups favoured support and elements of exercise. Participants were randomised to groups subsequent to these measures being taken and so we can only assume that these differences are a reflection of the relatively small sample. Of greater interest is the within-group change over the 16 weeks. The preferences of the control group remained steadily focused on diet at 16 weeks whereas the preferences of the intervention groups changed substantially. Common to both intervention groups was a clear move away from higher levels of support and towards favouring the intervention (ATN) diet. Both groups also favoured an independent supervised exercise programme at baseline but at 16 weeks they had lost interest in this. This, together with the relative disinterest in support, suggests that participants may have suffered intervention fatigue. We had expected support to remain important to Group B because of its imminent loss at 16 weeks but this was not the case.

Table 2 shows the breakdown of preferences for the two intervention groups for all periods. $\dagger$ Group A had improved explained variance at 12 months $(\rho=0 \cdot 14)$, which may reflect some convergence in their preferences with the longer exposure to the intervention through the follow-up sessions.

The move away at 16 weeks from preferring individual, supervised exercise towards self-managed exercise continued at 12 months, particularly for Group A that also avoided group-based exercise programmes at this point.

$\dagger$ The control group is not included because preferences were not collected for the third cohort at 12 months. On a reduced sample of the control group $^{(8)}$ at 12 months, diet continued to be the only significant attribute (serves, $b=1.020, P=0.001$; weekly, $b=0.648, P=0.037$; ATN, $b=0 \cdot 843, P=0 \cdot 018)$. 
Table 1 Attribute weights for choice of most preferred exercise and diet programme

\begin{tabular}{|c|c|c|c|c|c|c|c|c|c|c|c|c|}
\hline & \multicolumn{4}{|c|}{ Control (n 18) } & \multicolumn{4}{|c|}{ Group A (n 21) } & \multicolumn{4}{|c|}{ Group B (n 18) } \\
\hline & \multicolumn{2}{|c|}{ Baseline } & \multicolumn{2}{|c|}{16 weeks } & \multicolumn{2}{|c|}{ Baseline } & \multicolumn{2}{|c|}{16 weeks } & \multicolumn{2}{|c|}{ Baseline } & \multicolumn{2}{|c|}{16 weeks } \\
\hline & $b$ & $t$ & $b$ & $t$ & $b$ & $t$ & $b$ & $t$ & $b$ & $t$ & $b$ & $t$ \\
\hline \multicolumn{13}{|l|}{ Exercise structure* } \\
\hline Daily $30 \mathrm{~min}$ & $0 \cdot 261$ & $1 \cdot 28$ & 0.029 & $0 \cdot 20$ & 0.451 & $2 \cdot 02$ & $0 \cdot 245$ & $1 \cdot 00$ & $0 \cdot 384$ & $2 \cdot 03$ & -0.016 & -0.07 \\
\hline Weekly $3 \mathrm{~h}$ & -0.014 & -0.06 & 0.433 & $1 \cdot 90$ & $-0 \cdot 131$ & $-0 \cdot 40$ & $-0 \cdot 101$ & $-0 \cdot 30$ & $0 \cdot 400$ & 1.98 & $-0 \cdot 160$ & -0.47 \\
\hline Weekly $5 \mathrm{~h}$ & -0.035 & $-0 \cdot 17$ & $0 \cdot 167$ & $0 \cdot 84$ & 0.322 & $1 \cdot 21$ & -0.039 & $-0 \cdot 15$ & 0.336 & $1 \cdot 49$ & -0.142 & -0.45 \\
\hline \multicolumn{13}{|l|}{ Exercise contextt } \\
\hline Alone set programme & $0 \cdot 183$ & $0 \cdot 72$ & $-0 \cdot 275$ & -0.98 & 0.441 & $2 \cdot 26$ & -0.077 & $-0 \cdot 48$ & $0 \cdot 733$ & $3 \cdot 04$ & 0.085 & 0.49 \\
\hline Friends/group no programme & -0.008 & -0.03 & $-0 \cdot 186$ & -0.63 & 0.438 & $2 \cdot 34$ & $0 \cdot 014$ & 0.06 & 0.266 & 1.04 & -0.020 & -0.08 \\
\hline Committed group programme & -0.255 & -0.66 & -0.438 & $-1 \cdot 12$ & 0.246 & 0.78 & -0.326 & $-1 \cdot 17$ & 0.257 & 0.92 & -0.455 & $-1 \cdot 74$ \\
\hline \multicolumn{13}{|c|}{ Diet preferenceł } \\
\hline Daily serves & $0 \cdot 825$ & $3 \cdot 31$ & $0 \cdot 941$ & $4 \cdot 50$ & 0.390 & $1 \cdot 75$ & 0.410 & $1 \cdot 80$ & 0.403 & $1 \cdot 49$ & $0 \cdot 653$ & $2 \cdot 07$ \\
\hline Weekly meal programme & $0 \cdot 845$ & $4 \cdot 36$ & $0 \cdot 812$ & $4 \cdot 73$ & 0.452 & $2 \cdot 01$ & $0 \cdot 783$ & $2 \cdot 58$ & 0.354 & $1 \cdot 35$ & $0 \cdot 349$ & $2 \cdot 03$ \\
\hline ATN: small modifications & $0 \cdot 647$ & $2 \cdot 52$ & $0 \cdot 751$ & $2 \cdot 12$ & 0.377 & $1 \cdot 50$ & 0.940 & $3 \cdot 41$ & $0 \cdot 310$ & $0 \cdot 88$ & $0 \cdot 825$ & $2 \cdot 82$ \\
\hline \multicolumn{13}{|l|}{ Outcomes§ } \\
\hline $0.25 \mathrm{~kg}$, no body change & $-0 \cdot 141$ & $-0 \cdot 72$ & $-0 \cdot 199$ & $-1 \cdot 15$ & $-0 \cdot 196$ & -1.09 & $-0 \cdot 360$ & $-2 \cdot 70$ & $-0 \cdot 227$ & $-1 \cdot 15$ & $-0 \cdot 244$ & $-1 \cdot 62$ \\
\hline $0.5 \mathrm{~kg}$, no body change & -0.052 & -0.33 & -0.064 & -0.34 & $0 \cdot 118$ & $0 \cdot 86$ & $-0 \cdot 171$ & $-1 \cdot 80$ & $0 \cdot 188$ & $1 \cdot 00$ & -0.096 & -0.47 \\
\hline $0.25 \mathrm{~kg}$, body change & 0.022 & $0 \cdot 13$ & $-0 \cdot 186$ & $-1 \cdot 12$ & $0 \cdot 179$ & $1 \cdot 19$ & -0.185 & $-1 \cdot 42$ & $-0 \cdot 100$ & -0.65 & -0.201 & $-1 \cdot 28$ \\
\hline Weekly/monthly supportll & $0 \cdot 247$ & $1 \cdot 38$ & $-0 \cdot 113$ & $-0 \cdot 86$ & 0.460 & $2 \cdot 92$ & $0 \cdot 154$ & $1 \cdot 49$ & 0.432 & $2 \cdot 93$ & $0 \cdot 192$ & $1 \cdot 33$ \\
\hline Extra $\$ A \cup 15 / 7$ per d & $-0 \cdot 107$ & $-1 \cdot 24$ & -0.063 & $-0 \cdot 81$ & $-0 \cdot 107$ & $-1 \cdot 50$ & $-0 \cdot 114$ & $-1 \cdot 27$ & -0.003 & -0.05 & $-0 \cdot 112$ & $-2 \cdot 11$ \\
\hline No. of observations & \multirow{3}{*}{\multicolumn{2}{|c|}{$\begin{array}{c}864 \\
-316 \cdot 4 \\
-297.2\end{array}$}} & \multirow{3}{*}{\multicolumn{2}{|c|}{$\begin{array}{c}864 \\
-316 \cdot 4 \\
-292 \cdot 8\end{array}$}} & \multirow{3}{*}{\multicolumn{2}{|c|}{$\begin{array}{l}1008 \\
-369 \cdot 1 \\
-342 \cdot 9\end{array}$}} & \multirow{3}{*}{\multicolumn{2}{|c|}{$\begin{array}{l}1008 \\
-369 \cdot 1 \\
-343 \cdot 2\end{array}$}} & \multirow{3}{*}{\multicolumn{2}{|c|}{$\begin{array}{c}864 \\
-316 \cdot 4 \\
-297 \cdot 3\end{array}$}} & \multicolumn{2}{|c|}{864} \\
\hline 니_0 & & & & & & & & & & & -316 & $6 \cdot 4$ \\
\hline LI & & & & & & & & & & & \multicolumn{2}{|c|}{$-296 \cdot 8$} \\
\hline Pseudo $\rho$ & & 0.06 & \multicolumn{2}{|c|}{$\begin{array}{r}-292 \cdot 8 \\
0.07\end{array}$} & \multicolumn{2}{|c|}{$\begin{array}{r}-342.9 \\
0.07\end{array}$} & & 0.07 & \multicolumn{2}{|c|}{$\begin{array}{r}-297 \cdot 3 \\
0.06\end{array}$} & & 0.06 \\
\hline
\end{tabular}

${ }^{*}$ Reference $=45 \mathrm{~min} / \mathrm{d}$.

tReference $=$ alone no programme

$\ddagger$ Reference $=$ daily calories.

\$Reference $=0.5 \mathrm{~kg}$, body change

IIReference $=6$ months.
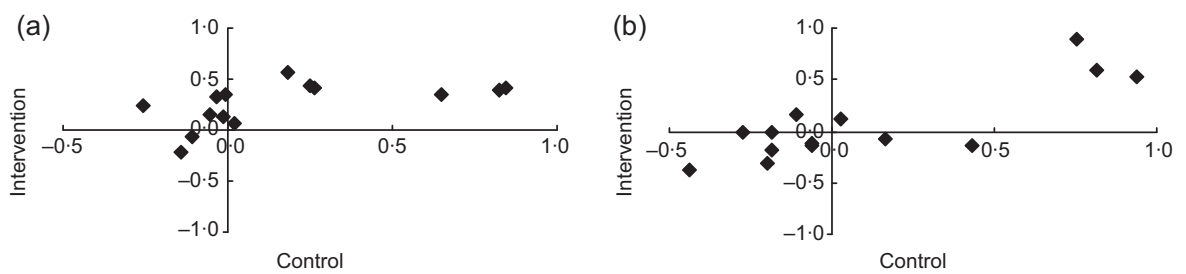

Fig. 1 Pattern of coefficients for control and intervention groups at (a) baseline and (b) 16 weeks

However, this was not the case for support, which again became an important element in programme choice for Group A. Outcomes were not a major choice factor for either group at baseline and 12 months, but Group A indicated a clear preference for higher weight loss and body shape change at 16 weeks which may reflect renewed resolve following assessment; however, we would expect the same to be true for Group B and this is less evident. Cost became a significant negative factor for Group B at 16 weeks and then for Group A at 12 months, which is in line with their exit points.

\section{Intervention outcome and preferences}

A key measure used in the intervention to assess changes in metabolic syndrome was abdominal fat loss as assessed by dual-energy X-ray absorptiometry (DEXA), which measures bone density and body fat with high levels of precision. This was used to divide the intervention sample of thirty-nine participants into three groups based on percentage change in their abdominal fat over the 12 months: Gainers, Neutral (no loss to $<5 \%$ loss) and Losers ( $\geq 5 \%$ loss), with Losers and Gainers the groups of interest for analysis.

No differences were observed in the proportion of Gainers and Losers across the two experimental groups $\left(\chi^{2}=1 \cdot 0612\right)$ and abdominal fat loss was not associated with age $(r=0 \cdot 09)$. Table 3 gives summary statistics for the sample of Losers and Gainers.* There is some indication that participants who were married or living with a partner were more likely to be categorised as Gainers whereas those divorced were more likely to be Losers, but the sample is small ( $n$ 29). Losers' average heart rate

\footnotetext{
* Note these results apply only to this subsample of the intervention.
} 
Table 2 Comparison of preference patterns for the intervention groups over 12 months

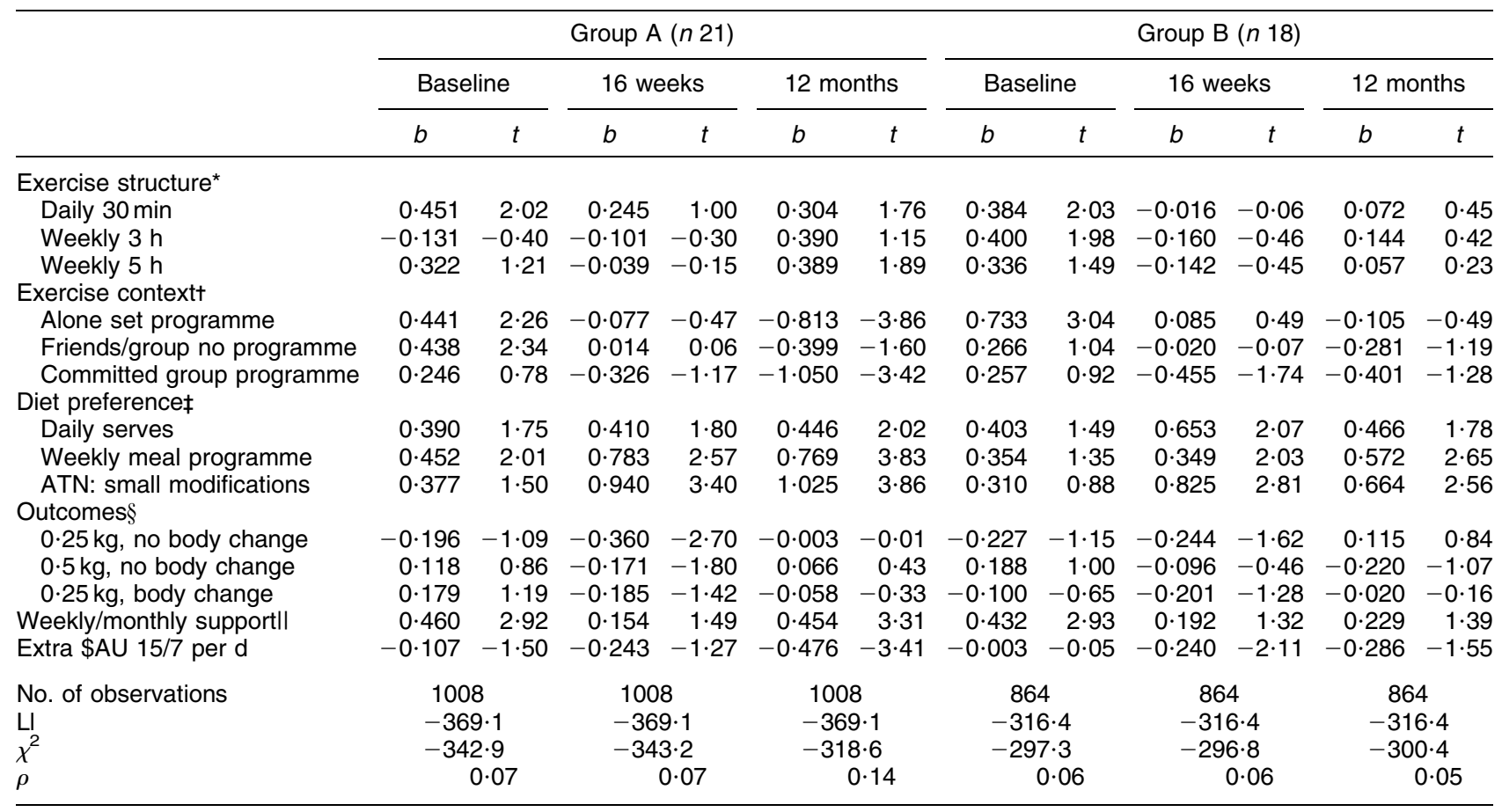

${ }^{\star}$ Reference $=45 \mathrm{~min} / \mathrm{d}$.

tReference $=$ alone no programme

$\ddagger$ Reference $=$ daily calories.

$\S$ Reference $=0.5 \mathrm{~kg}$, body change.

IIReference $=6$ months.

Table 3 Summary statistics for Losers and Gainers

\begin{tabular}{|c|c|c|}
\hline & Losers & Gainers \\
\hline Female $(n)$ & 10 & 12 \\
\hline Male $(n)$ & 4 & 3 \\
\hline Married/de facto $(n)$ & 6 & 12 \\
\hline Single/divorced $(n)^{\prime}$ & 8 & 3 \\
\hline Mean age (years) & $47(\mathrm{sD} 10)$ & 46 (sD 9) \\
\hline \multicolumn{3}{|c|}{ Mean body fat mass $(\mathrm{kg})$} \\
\hline Baseline & $42 \cdot 7(\mathrm{SD} 14 \cdot 9)$ & $47 \cdot 8(\mathrm{SD} 15 \cdot 8)$ \\
\hline 16 weeks & $38.4(S D 14.2)$ & $47 \cdot 6(S D 16 \cdot 4)$ \\
\hline 12 months* & $37 \cdot 4(\operatorname{SD} 13 \cdot 1)$ & $49 \cdot 9(\mathrm{SD} 16 \cdot 4)$ \\
\hline \multicolumn{3}{|c|}{ Mean heart rate (beats/min) } \\
\hline Baseline & 64 (SD 6) & $63(\mathrm{sD} 10)$ \\
\hline 16 weeks & 63 (SD 11) & $60(\mathrm{sD} 8)$ \\
\hline 12 months & $61(\mathrm{SD} 8)$ & $63(\mathrm{SD} 11)$ \\
\hline Total $n$ & 14 & 15 \\
\hline
\end{tabular}

${ }^{*}$ Mean body fat mass at 12 months significantly different between Losers and Gainers $(P<0.05)$.

(fitness) and general body fat mass (as measured by DEXA) decreased over the study, whereas Gainers had higher initial body fat mass and either maintained or gained fat at 16 weeks. The few Gainers that did have losses in the first 16 weeks regained weight at 12 months (six of the fifteen Gainers). Within periods the only significant difference between Losers and Gainers was for body fat mass at 12 months $(P=0 \cdot 03)$.

Table 4 compares the preferences of the two groups over 12 months and Fig. 2 plots attribute coefficients for Losers $v$. Gainers. At baseline the spread of coefficients indicates there were marked differences in the pattern of responses for each group, suggesting that their approach to choosing programmes was different. At 16 weeks and 12 months the pattern was more one of relative emphasis.

At baseline Gainers focused almost exclusively on supervised individual exercise and a high level of support; in effect, they gave themselves over to the programme staff. At 16 weeks this enthusiasm had waned and they were clearly favouring self-directed exercise rather than supervised or group exercise. This trend continued at 12 months as did the negative effect of cost, which emerged as important at 16 weeks. The intervention diet, once introduced, was the favoured diet over the study.

While Losers favoured higher levels of support and supervised exercise at baseline, they also uniformly considered other factors such as type of diet and exercise duration. At 16 weeks they also moved away from supervised exercise programmes and group exercise was avoided. Preference for high levels of support waned somewhat but only marginally so. Losers had a clear focus on higher weight loss and body shape change at 16 weeks, which may be a function of their having experienced successful outcomes. The intervention diet was significant at 16 weeks and remained so at 12 months, but they also retained a preference for more structured diets over the 12-month time frame. Cost was not a factor in choice of programme for Losers. 
Table 4 Comparison of preference patterns for Losers and Gainers over 12 months

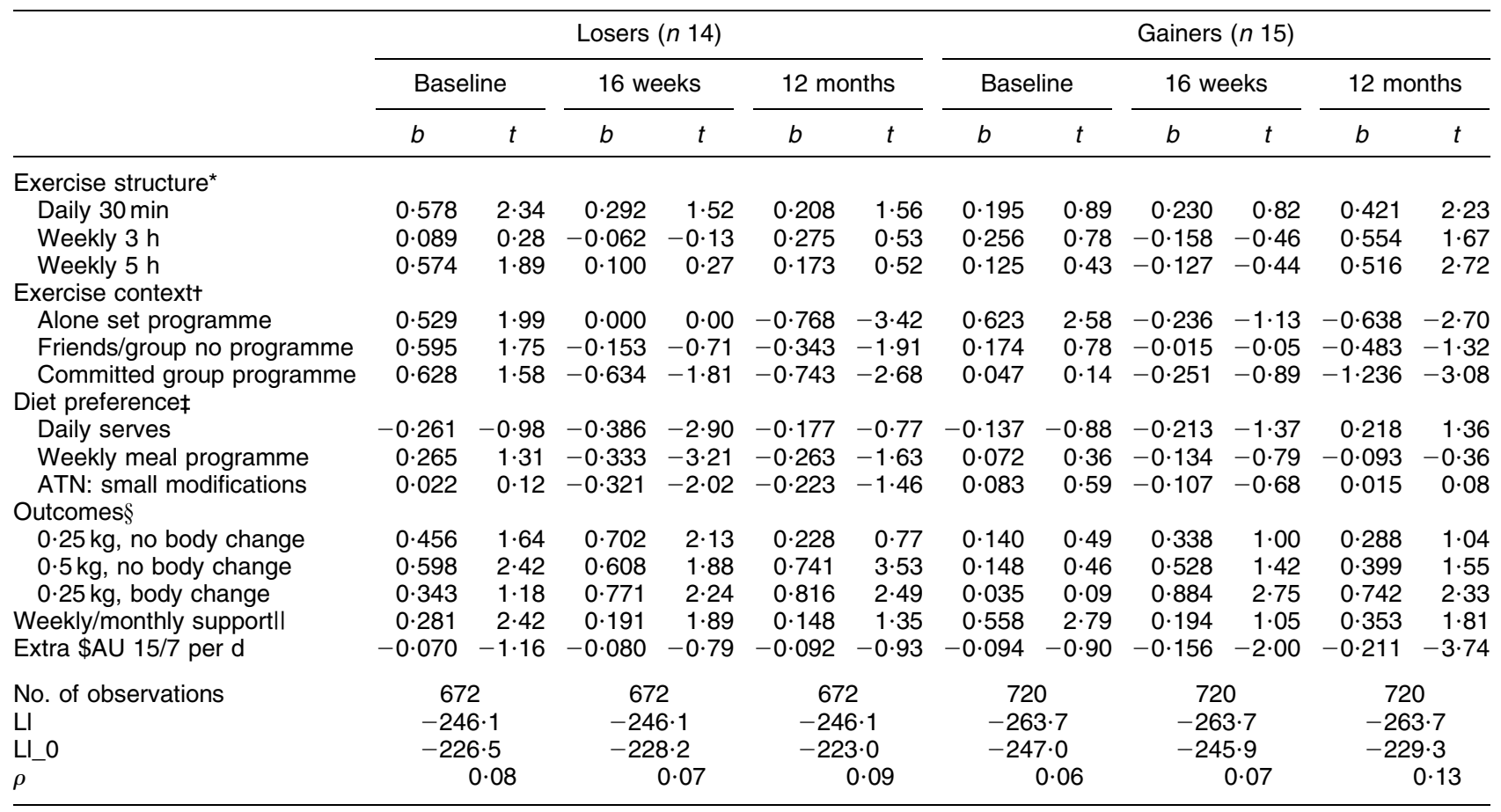

${ }^{*}$ Reference $=45 \mathrm{~min} / \mathrm{d}$.

tReference $=$ own programme flexible.

‡Reference $=$ daily fixed menu based on calories.

$\S$ Reference $=0.5 \mathrm{~kg}$, body change.

IIReference $=6$ months.

(a)

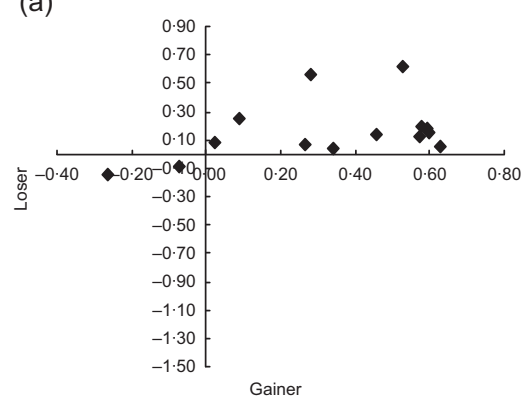

(b)

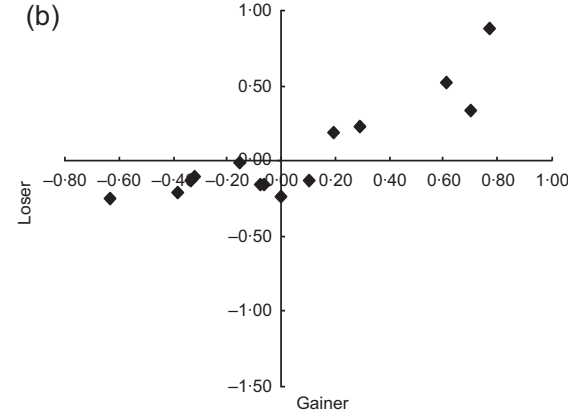

(c)

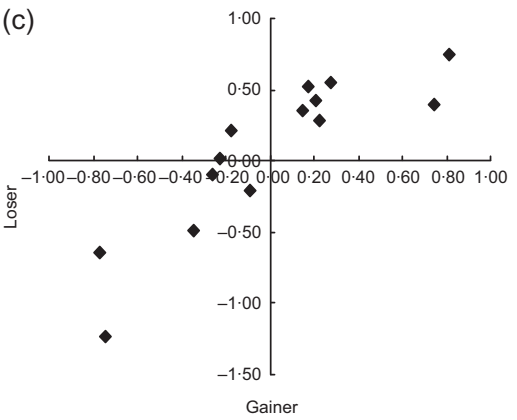

Fig. 2 Pattern of coefficients for Gainers and Losers at (a) baseline, (b) 16 weeks and (c) 12 months

\section{Discussion and implications}

The research reported herein used the Stated Preference method to elicit preferences for exercise and diet programmes from participants in a trial lifestyle invention. The aim was to explore how participants' experiences with the intervention influenced their preferences for various attributes of lifestyle-type programmes and whether systematic differences between successful and unsuccessful outcomes could be identified.

The pattern of preferences over time captured the initial enthusiasm of participants, including eagerness for support and supervision, followed by a gradual waning during the course of the intervention. The strong negative response from Group A (follow-up group) at 12 months to exercise that was supervised and/or required a commitment may reflect participation fatigue, although organised exercise was not part of the follow-up and it is notable that Group A showed renewed interest in support. Wadden et al. ${ }^{(11)}$ argue the need for interventions to be longer and have greater follow-up support, while other studies have found high attrition and loss of interest in protracted or repeated interventions ${ }^{(2,12)}$. The results of the current study have elements consistent with both views. Most participants clearly became fatigued with an intensive programme at 16 weeks, but closer inspection of the results revealed that Group B Losers actually preferred high levels of support at this point while at 
12 months it was Group A Gainers that were responsible for the increased emphasis on higher support. Thus, in the present study, support resources were seen as important by Losers, even though they appeared not to need them, whereas those who saw no need for support seemed not to benefit from the intermittent support provided, at least in terms of improved metabolic fitness.

The intervention diet - small modifications and healthier eating - became a clear favourite for Gainers but Losers continued to choose the more structured diets as well. Neither group favoured the most restrictive diet (calorie control). Mela ${ }^{(13)}$ argues that rigid adherence to a strict diet is less successful than a flexible approach, while Read et al. argue that focusing on each day can aid self-control ${ }^{(14)}$. The intervention diet recommended that participants monitor their energy intake and output but left decisions on food intake to individuals. The results suggest that Losers were able to maintain greater control over their diet, even with elements of flexibility.

The emergence of cost as an issue for Group B at 16 weeks and then for Group A at 12 months was consistent with the loss of resources at the end of the intervention and/or follow-up period, and suggests a potential barrier to continuation of lifestyle changes for those who are cost-sensitive. The foods provided as part of the intervention were of high quality and easy to use but they were also expensive. This may have contributed to increased sensitivity to cost and represents a potential barrier to individuals maintaining a diet. Gainers were more cost-sensitive than Losers, but there were some difference in participant characteristics (more single/ divorced Losers) that may also have contributed to this ${ }^{(15)}$. Further research is needed to determine the nature of perceived cost constraints and whether they reflect, at least in part, heavier reliance on external rather than internal resources to manage lifestyle change.

While no firm conclusions can be drawn as to differences in the characteristics or preferences of Gainers and Losers, Losers did seem to be more methodical in their approach, took an active interest in their programme, and were more self-directed. This is consistent with Elfhag and Rossner, who found participants who were more ordered and deliberative had higher weight loss ${ }^{(16)}$. Gainers tended to demonstrate greater reliance on the programme at baseline and exhibited little consideration of attributes other than external support and supervision ${ }^{(15)}$. At 12 months Gainers exhibited more consistent preferences and wider consideration of the attributes of lifestyle change and less focus on external inputs. While it is possible that their responses reflect an intervention effect, it may also reflect a greater awareness of what is needed to improve their lifestyle.

\section{Limitations}

While discrete choice experiments are often presented as predictors of actual behaviour, this is less likely to be the case in the context of complex behavioural change which is inherently experiential and requires non-hedonistic control of behaviour. In the current research we elicited preferences at baseline, 16 weeks and 12 months, and so participants' preferences were partly informed by experience with the intervention and reflected key issues for respondents at each point over the study. This was the intent of the study but it does anchor the results to this particular intervention.

The study was based on a small sample and was exploratory in nature. Future research using this method might make greater use of labelled programmes (e.g. Curves, Weight Watchers, etc.) and alternative specific attributes rather than a generic set of attributes. This would enable greater depth of analysis of the probabilities of choosing and maintaining different programmes and their association with actual outcomes.

Participants had no difficulty in responding to the programme scenarios but anecdotal feedback indicated they found the task repetitive and therefore tiresome. There was no evidence that this affected the results apart from increasing the error component. The time between responding to the scenarios was sufficient for participants to recognise the task but there was no evidence that they recalled in detail their earlier responses.

\section{Acknowledgements}

Project funding was received from the Australian Technology Network of Universities. This research was not subject to conflicts of interest. K.O. was the primary researcher. M.H. and R.V. were part of research team, providing advice throughout the study and editorial support. T.P. conducted the trial lifestyle intervention as part of her doctoral work under G.M. and both provided assistance in the construction and conduct of this study. We would like to thank Debra Misan and Kate Warren for their assistance with data collection and the study participants.

\section{References}

1. Byrne S, Cooper Z \& Fairburn C (2003) Weight maintenance and relapse in obesity: a qualitative study. Int $J$ Obes Relat Metab Disord 27, 955-962.

2. Jeffery RW, Kelly KM, Rothman AJ, Sherwood NE \& Boutelle KN (2004) The weight loss experience: a descriptive analysis. Ann Behav Med 27, 100-106.

3. Hetherington MM (2007) Individual differences in the drive to overeat. Nutr Bull 32, 14-21.

4. Kuchler F \& Lin BH (2002) The influence of individual choices and attitudes on adiposity. Int J Obes Relat Metab Disord 26, 1017-1022.

5. Serdula MK, Mokdad AH, Williamson DF, Galuska DA, Mendlein JM \& Heath GW (1999) Prevalence of attempting weight loss and strategies for controlling weight. JAMA 282, 1353-1358.

6. Williams L, Germov J \& Young A (2007) Preventing weight gain: a population cohort study of the nature and 
effectiveness of mid-age women's weight control practices. Int J Obes (Lond) 31, 978-986.

7. Lorig K (1999) Living Improvements for Everyone: A Course in Chronic Disease Self-Management. Stanford, CA: Stanford Patient Education Research Centre, Leland Stanford Junior University.

8. National Health and Medical Research Council (2003) Dietary Guidelines for Australian Adults. Canberra: NHMRC.

9. Pettman TL, Misan GM, Owen K, Warren K, Coates AM, Buckley JD \& Howe PR (2008) Self-management for obesity and cardio-metabolic fitness: description and evaluation of the lifestyle modification program of a randomised controlled trial. Int J Behav Nutr Phys Act 5, 53.

10. Saris WH, Blair SN, van Baak MA et al. (2003) How much physical activity is enough to prevent unhealthy weight gain? Outcome of the IASO 1st Stock Conference and consensus statement. Obes Rev 4, 101-114.
11. Wadden TA, Butryn ML \& Byrne KJ (2004) Efficacy of lifestyle modification for long-term weight control. Obes Res 12, Suppl., 151S-162S.

12. Jeffery RW \& Levy RL (2008) Maintenance: theoretical and empirical concepts. Ann Behav Med 35, S97.

13. Mela DJ (2001) Determinants of food choice: relationships with obesity and weight control. Obes Res 9, Suppl. 4, 249S-255S

14. Read D, Loewenstein G \& Rabin M (1999) Choice bracketing. J Risk Uncertain 19, 171.

15. Brownell KD \& Cohen LR (1995) Adherence to dietary regimens. 2: Components of effective interventions. Behav Med 20, 155-164.

16. Elfhag K \& Rossner S (2005) Who succeeds in maintaining weight loss? A conceptual review of factors associated with weight loss maintenance and weight regain. Obes Rev $\mathbf{6}$, $67-85$.

\section{Appendix}

\section{Example of a bypothetical programme}

\begin{tabular}{|c|c|c|c|}
\hline \multicolumn{4}{|l|}{ D3 } \\
\hline & Plan A & Plan B & Plan C \\
\hline $\begin{array}{l}\text { Amount of } \\
\text { exercise }\end{array}$ & $\begin{array}{l}30 \text { minutes each day. 5-6 } \\
\text { days per week. }\end{array}$ & $\begin{array}{l}\text { No daily commitment but } 3 \\
\text { hours over a week. }\end{array}$ & $\begin{array}{l}45 \text { minutes each day. } 5-6 \\
\text { days per week. }\end{array}$ \\
\hline $\begin{array}{l}\text { Where you } \\
\text { exercise }\end{array}$ & $\begin{array}{l}\text { You commit to a group } \\
\text { exercise program at a } \\
\text { club/gym/community } \\
\text { centre. }\end{array}$ & $\begin{array}{c}\text { You commit to a } \\
\text { structured program } \\
\text { designed for you to do on } \\
\text { your own }\end{array}$ & $\begin{array}{l}\text { You arrange to exercise } \\
\text { with a friend(s) or attend } \\
\text { group classes but no } \\
\text { specific program }\end{array}$ \\
\hline Diet plan & $\begin{array}{l}\text { No targets or fixed menus } \\
\text { but small adjustments in } \\
\text { quantity and type of food } \\
\text { eaten each day. }\end{array}$ & $\begin{array}{l}\text { Weekly diet plan with a } \\
\text { range of meal options that } \\
\text { you can choose from. }\end{array}$ & $\begin{array}{l}\text { Daily target of calories or } \\
\text { energy and carbohydrates. } \\
\text { Specific menu for each } \\
\text { day. }\end{array}$ \\
\hline Monitoring & $\begin{array}{l}\text { Fortnightly or } 1 \text { month } \\
\text { checks. }\end{array}$ & 4-6 month checks. & $\begin{array}{l}\text { Fortnightly or } 1 \text { month } \\
\text { checks. }\end{array}$ \\
\hline $\begin{array}{c}\text { Estimated } \\
\text { cost }\end{array}$ & No extra cost & No extra cost & $\$ 15$ per week \\
\hline $\begin{array}{l}\text { Likely } \\
\text { outcome }\end{array}$ & $\begin{array}{c}\text { Steady weight loss each } \\
\text { week of about } 1 / 4 \mathrm{~kg} \text {. Body } \\
\text { Shape improved (eg. down } \\
1 \text { clothes size in first } 4 \\
\text { months) }\end{array}$ & $\begin{array}{c}\text { Steady weight loss each } \\
\text { week of about } 1 / 2 \mathrm{~kg} \text {. Body } \\
\text { Shape improved (eg. down } \\
1 \text { clothes size in first } 4 \\
\text { months) }\end{array}$ & $\begin{array}{l}\text { Steady weight loss each } \\
\text { week of about } 1 / 4 \mathrm{~kg} \text {. No } \\
\text { obvious change in body } \\
\text { shape for the first } 4 \\
\text { months but increased } \\
\text { fitness and wellbeing. }\end{array}$ \\
\hline \multicolumn{4}{|c|}{ Q1: Which of the three (3) Plans do you: } \\
\hline \multicolumn{2}{|c|}{ Q2: Which do you: } & LEAST LIKE & Plan __ \\
\hline \multicolumn{4}{|c|}{$\begin{array}{l}\text { Q3: You are looking for an exercise and diet plan that you could maintain for ONE (1) } \\
\text { YEAR? Is the plan you MOST prefer one that you could maintain for this time? (If } \\
\text { NO circle } 0 \% \text {. Otherwise circle how confident you are that you can maintain the plan) }\end{array}$} \\
\hline $0 \%$ & $20 \%$ & $60 \%$ & $100 \%$ \\
\hline
\end{tabular}

